\title{
The effects of ectomycorrhizal status on carbon dioxide assimilation capacity, water-use efficiency and response to transplanting in seedlings of Pseudotsuga menziesii (Mirb) Franco
}

\author{
JM Guehl 1, J Garbaye 2 \\ 1 INRA Centre de Recherches de Nancy, Laboratoire de Bioclimatologie \\ et d'Écophysiologie Forestières, 54280 Champenoux; \\ 2 INRA Centre de Recherches de Nancy, Laboratoire de Microbiologie Forestière, \\ F 54280 Champenoux, France
}

(Received 30 March 1990; accepted 5 December 1990)

\begin{abstract}
Summary - One year-old Douglas fir seedlings, mycorrhizal with Laccaria laccata or with Thelephora terrestris and grown at two levels of phosphorus in the nutrient solution (10 and $40 \mathrm{mg}^{-1} \mathrm{P}$ ), were compared for water relations and gas exchange before and after transplanting in non-limiting water conditions. The results show that $i), L$ laccata is more efficient than $T$ terrestris in increasing photosynthesis and water use efficiency, ii), phosphorus deficiency reduces photosynthesis and water use efficiency, iii), the stimulating effect of $L$ laccata on photosynthesis and water use efficiency is, at least partly, due to the improvement of phosphorus nutrition, iv), the photosynthesis reduction resulting from transplanting is due to a non-stomatal mechanism, and $v$ ), the recovery of photosynthesis involves the regrowth of the external mycelium of mycorrhizas. These results are discussed from the viewpoint of the plant-fungus relationships.
\end{abstract}

ectomycorrhizae / phosphorus nutrition / $\mathrm{CO}_{2}$ assimilation / water-use efficiency / transplanting

Résumé - Effets du statut mycorhizien sur la capacité d'assimilation de $\mathrm{CO}_{2}$, l'efficience d'utilisation de l'eau et la réponse à la transplantation de semis de Pseudotsuga menziesii (Mirb) Franco. Des semis de 1 an de douglas, mycorhizés par Laccaria laccata ou Thelephora terrestris ont été élevés durant une saison de croissance à 2 niveaux de phosphore dans la solution nutritive $\left(10\right.$ et $\left.40 \mathrm{mg}^{\circ}{ }^{-1} \mathrm{P}\right)$ et ont été comparés du point de vue des relations hydriques et des échanges gazeux avant et après transplantation (à 2 dates différentes, en octobre et en février) en conditions hydriques non limitantes. $A$ faible niveau de phosphore, les plants inoculés par $\mathrm{L}$ laccata avaient une surface foliaire plus importante que les plants mycorhizés par T terrestris (tableau I) et étaient également caractérisés par des taux d'assimilation de $\mathrm{CO}_{2}$ et d'efficience photosynthétique d'utilisation de l'eau plus élevés (tableau Il et fig 1). La carence en phosphore réduit la photosynthèse et l'efficience d'utilisation de l'eau (tableau II, fig 1). L'effet stimulant de L laccata sur l'efficience de l'eau est dû, au moins en partie, à l'amélioration de la nutrition en phosphore (fig 7 et 9). 
La réduction de la photosynthèse consécutive à la transplantation (fig 2), bien qu'accompagnée par une fermeture stomatique (fig 3), est dûe essentiellement à un mécanisme non stomatique (fig 4) et n'est pas liée à une altération de l'état hydrique et nutritionel (fig 7 et 8) des plants. Le rétablissement de la photosynthèse après transplantation est concomitant à la régénération racinaire (fig 5), mais son déterminisme implique également la reprise d'activité du champignon (fig 6). Ces résultats sont discutés du point de vue des relations plante-champignon.

ectomycorhize / nutrition phosphatée / assimulation de $\mathrm{CO}_{2}$ / efficience de l'eau / transplantation

\section{INTRODUCTION}

Ectomycorrhizal symbiosis is essential for nursery-grown conifer seedlings and is determinant for plant survival and growth after outplanting (Marx et al, 1977; Le Tacon et al, 1988). It is also known that different fungal associates do not provide the same benefit in this respect, through mechanisms as diverse as improving mineral absorption and assimilation affecting hormonal balance in the plant, enhancing the contact between roots and soil, and protecting roots against disease (Chalot $e t$ al, 1988). This paper describes and discusses the physiological status of one year-old Douglas fir seedlings, associated with two different ectomycorrhizal fungi and grown at two phosphorous levels, before they were lifted. The behaviour of the same seedlings transplanted in controlled conditions was also considered.

The results presented here are part of a project which is aimed at understanding the role played by the fungal associates during the transplanting shock suffered by forest plants when outplanted, even in non-limited water supply conditions (Guehl et al, 1989). Gas exchange parameters $\left(\mathrm{CO}_{2}\right.$ assimilation rate, transpiration rate, water-use efficiency) were used as physiological criteria for monitoring the behaviour of plants with different ectomycorrhizal status.

\section{MATERIALS AND METHODS}

\section{Plant material}

Douglas fir (Pseudotsuga menziesii (Mirb) Franco) seedlings were grown in the summer in a glasshouse, in $95 \mathrm{ml}$ containers filled with 1/1 ( $\mathrm{v}$ / v) vermiculite-sphagnum peat mix inoculated with the ectomycorrhizal fungus Laccaria laccata or non-inoculated. Inoculum was mycelium aseptically grown for two months in glass jars, in a vermiculite-peat substrate moistened with nutrient medium. Twenty per cent $(v / v)$ inoculum was mixed with the potting mix before filling the containers. Each inoculation treatment was watered with a complete nutrient solution containing either 10 or $40 \mathrm{mg} \cdot \mathrm{ml}^{-1}$ phosphorus as $\mathrm{Na}_{2} \mathrm{PO}_{4}$. Each fungus-phosphorus level treatment involved 120 seedlings. At the end of September, when growth stopped and buds were set up, a random sample of 6 seedlings per treatment was observed for mycorrhizas with a stereomicroscope after gently washing the root systems. Ectomycorrhizal development was rated according to a four-level scale (0: no mycorrhiza; 1: rare mycorrhizas; 2 : several conspicuous mycorrhizal clusters and/or mycorrhizas disseminated throughout the root system; 3: mycorrhizas abundant in all parts of the root system). Three treatments were chosen for subsequent measurements and analysis:

- Tt low phosphorus level, non inoculated, mycorrhizal with contaminant Thelephora terrestris (mycorrhizal rating: 1.6);

-TtP: high phosphorus level, non-inoculated, mycorrhizal with $T$ terrestris (rating: 2.4); ]

- Ll: low phosphorus level, inoculated with Laccaria laccata, predominantly mycorrhizal with $L$ 
laccata (rating: 2.6) and slightly contaminated with $T$ terrestris.

\section{Sampling and experimental set-up}

The seedlings were kept in a frostless glasshouse during winter, without fertilization, under conditions such that aerial growth was stopped from October to March. Two sets of measurements were performed: in November and in February. At each date, 20 plants per treatment were randomly picked among the $50 \%$ tallest ones. Before transplanting, $6-8$ of these plants were used for gas exchange measurements and for determining the phosphorus and nitrogen content of the needles. The 12 remaining plants were used for gas exchange measurements and transplanted as follows: they were immediately lifted, their roots washed, and mycorrhizal development was quantified. The growing white root tips were sectioned, and the seedlings were planted in sphagnum peat in flat $(3 \mathrm{~cm}$ thick) containers with a transparent wall allowing observation of the roots. These containers were placed in a climate chamber under the following environmental conditions: photoperiod, $16 \mathrm{~h}$; air temperature, $22 \pm 0.2^{\circ} \mathrm{C}$ (d) and $16.0 \pm 0.2^{\circ} \mathrm{C}$ (night); photosynthetic photon flux density (400$700 \mathrm{~nm}$ ), $400 \mu \mathrm{mol} \mathrm{m} \mathrm{m}^{-2} \mathrm{~s}^{-1}$ provided by fluorescent tubes; relative air humidity, $60 \%$ (day) and $90 \%$ (night); ambient $\mathrm{CO}_{2}$ concentration $\left(C_{2}\right)$, $420 \pm 30 \mu \mathrm{mol} \cdot \mathrm{mol}^{-1}$. They were watered twice a week with the $10 \mathrm{mg}^{-1} \mathrm{P}$ nutrient solution in order to maintain the moisture of the peat near field capacity.

Water status, gas exchange, root regeneration (number of elongated white tips), and regrowth of mycorrhizal extramatical mycelium (quantified according to the same rating scale as above) were assessed 4,11 and $18 \mathrm{~d}$ after transplanting.

At the end of each experiment, the seedlings were processed for dry weight and leaf area determination. Needles were then oven-dried $\left(60^{\circ} \mathrm{C}\right.$ for $\left.48 \mathrm{~h}\right)$ and mineral analyses were performed (February only).

\section{Water status and gas exchange measurements}

Predawn needle water potential $\left(\psi_{w p}\right)$ was determined on one needle per seedling prior to the gas exchange measurements by means of a Scholander pressure bomb specifically devised for measurements on individual conifer needles.

For the November experiment, the plants were taken from the climate room to a laboratory where gas exchange measurements were made by means of an open system consisting of three assimilation chambers connected in parallel in which the environmental factors could be controlled. Measurements were made at $22.0 \pm$

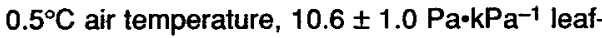
to-air water vapour molar fraction difference, $400 \mu \mathrm{mol} \cdot \mathrm{m}^{-2} \cdot \mathrm{s}^{-1}$ photosynthetic photon flux density $(400-700 \mathrm{~nm})$ and $350 \pm 5 \mu \mathrm{mol} \cdot \mathrm{mol}^{-1}$ ambient $\mathrm{CO}_{2}$ concentration $\left(C_{a}\right)$.

For the February experiment, gas exchange measurements were made in the climate room with a portable gas-exchange measurement system (Li-Cor 6200, Li-Cor, Lincoln, NE, USA). The $\mathrm{CO}_{2}$ concentration in the climate room was kept constant $\left(C_{\mathrm{a}}=425 \pm 15 \mu \mathrm{mol}^{\circ} \mathrm{mol}^{-1}\right)$.

Gas exchange parameters $\left(\mathrm{CO}_{2}\right.$ assimilation rate, $A$; leaf conductance for water vapour, $g$; intercellular $\mathrm{CO}_{2}$ concentration, $C_{i}$ ) were calculated with the classical equations (Caemmerer and Farquhar, 1981) taking into account simultaneous $\mathrm{CO}_{2}$ and $\mathrm{H}_{2} \mathrm{O}$ diffusion through the stomatal pores. Intercellular $\mathrm{CO}_{2}$ concentration $\left(C_{i}\right)$ calculations were performed in order to assess whether differences for $A$ between treatments and $A$ changes in response to transplanting were due to chloroplastic or to stomatal factors (Jones, 1985). Previous measurements made on conifers (unpublished data) did not show any patch pattern in stomatal closure, so that reliable $C_{i}$ calculations can be performed from leaf gas exchange data. More precisely, $\mathrm{CO}_{2}$ assimilation rate was considered in an $\left(A, C_{i}\right)$ graph as being at the intersection of two functions: $i)$, the photosynthetic $\mathrm{CO}_{2}$ demand function (D) which defines the mesophyll photosynthetic capacity and, ii), the photosynthetic $\mathrm{CO}_{2}$ supply function (Su) defining the diffusional limitation to $\mathrm{CO}_{2}$ as- 
similation. For determining the (D) functions, $C_{a}$ was varied stepwise and $A$ and $C_{i}$ were calculated for each step. The Su function is a line with an $x$-axis intercept approximately equal to $C_{a}$ and a negative slope approximately equal to $-g$ (Guehl and Aussenac, 1987). Water-use efficiency (WUE) was determined as the $A / g$ ratio.

At the end of the experiment, the seedlings were harvested and plant material was separated into different compartments (needles, stems and root systems). Each compartment was oven-dried at $60^{\circ} \mathrm{C}$ for $48 \mathrm{~h}$ and weighed. The dried needles were kept for mineral analysis.

Projected needle areas of the seedlings were determined with a video camera coupled to an image analyser ( $\Delta T$ area meter; $\Delta T$ devices, Cambridge, UK).

\section{Mineral analyses}

The total nitrogen content of the dried and ground needles was determined with a $\mathrm{C} / \mathrm{N}$ analyser (Model 1500; Carlo Erba, Italy). The values obtained with this technique are about $10 \%$ higher than those obtained with the Kjeldahl method. The phosphorus concentrations were determined after pressure digestion of the ground material with $100 \% \mathrm{HNO}_{3}$, at $170^{\circ} \mathrm{C}$ for $6 \mathrm{~h}$ (Schramel et al, 1980) with a direct current plasma emission spectrometer (Model Spectro Span 6; Beckman Instruments, USA).

\section{RESULTS}

\section{Plant size and biomass}

Data relative to the size and biomass of the February seedlings (before transplanting) are given in table I. Stem height was highest in the TtP and $L /$ treatments. Root collar diameter and total dry weight were significantly higher in TtP than in the other treatments, whereas there was no significant difference in the root/shoot ratio between the different treatments. Needle area was significantly higher in $T t P$ and $L I$ than in $T t$. The seedlings of the different treatments did not exhibit significant differences in their specific leaf dry weight (ratio of needle dry weight to needle area).

\section{Gas exchange and water-use efficiency}

Table II gives the mean values of $\mathrm{CO}_{2}$ assimilation rate $(A)$, stomatal conductance $(g)$ and water-use efficiency (WUE $=A / g$ ) in the different treatments before transplanting, in the 2 experiments. TtP and $L I$ exhibited $A$ values significantly higher than

Table I. Size, biomass dry weight characteristics, needle area and needle specific dry weight in the different treatments in February. In a given column, mean values not sharing a common letter are significantly different $(P<0.05)$. $n=11$ or 12 .

\begin{tabular}{ccccccc}
\hline Treatment & Stem height & $\begin{array}{c}\text { Root collar } \\
\text { diameter } \\
(\mathrm{mm})\end{array}$ & $\begin{array}{c}\text { Plant } \\
\text { dry weight } \\
(\mathrm{g})\end{array}$ & $\begin{array}{c}\text { Rootshoot } \\
\text { ratio } \\
\left(g^{\circ} \cdot \mathrm{g}^{-1}\right)\end{array}$ & $\begin{array}{c}\text { Needle area } \\
\left(10^{-2} \cdot \mathrm{m}^{2}\right)\end{array}$ & $\begin{array}{c}\text { Specifc leaf } \\
\text { dry weight } \\
\left(g^{\bullet} \mathrm{m}^{-2}\right)\end{array}$ \\
\hline $\mathrm{Tt}^{1}$ & $67 \mathrm{~b}$ & $1.3 \mathrm{~b}$ & $0.46 \mathrm{~b}$ & $1.50 \mathrm{a}$ & $0.12 \mathrm{~b}$ & $108 \mathrm{a}$ \\
$\mathrm{TtP}$ & $85 \mathrm{a}$ & $1.8 \mathrm{a}$ & $0.91 \mathrm{a}$ & $1.95 \mathrm{a}$ & $0.18 \mathrm{a}$ & $115 \mathrm{a}$ \\
$\mathrm{L}$ & $\mathrm{B} \mathrm{a}$ & $1.5 \mathrm{ab}$ & $0.60 \mathrm{~b}$ & $1.40 \mathrm{a}$ & $0.17 \mathrm{a}$ & $103 \mathrm{a}$ \\
\hline
\end{tabular}

$1 \mathrm{Tt}, T$ terrestris, $10 \mathrm{mg} \mathrm{l}^{-1} \mathrm{P} ; T t P, T$ terrestris, $40 \mathrm{mg} \mathrm{l}^{-1} \mathrm{P}, L, L$ laccata, $10 \mathrm{mg} \mathrm{I}^{-1} \mathrm{P}$ 
Table II. Carbon dioxide assimilation rate $(A)$, Stomatal conductance for water vapour $(g)$ and wateruse efficiency (WUE $=A / g$ ) in the different treatments in November 1988 and February 1989. Measurements were made just prior to transplanting (day 0 ). For each set of measurements mean values not sharing common letters are significantly different $(P<0.05), n=11$ or 12 .

\begin{tabular}{|c|c|c|c|}
\hline Treatment & $\underset{\left(\mu m o l \cdot m^{-2} \cdot s^{-1}\right)}{A}$ & $\underset{\left(m m o l \cdot m^{2} \cdot 5^{-1}\right)}{g}$ & $\begin{array}{c}\text { WUE } \\
\left(\mathrm{mmol}^{\circ} \mathrm{mol}^{-1}\right)\end{array}$ \\
\hline \multicolumn{4}{|l|}{ November } \\
\hline$T t^{1}$ & $3.44 \mathrm{c}$ & $97 \mathrm{~b}$ & $0.035 b$ \\
\hline$T t P$ & $7.3 \mathrm{a}$ & $121 \mathrm{a}$ & $0.061 \mathrm{a}$ \\
\hline$L I$ & $5.09 \mathrm{~b}$ & $97 \mathrm{~b}$ & $0.052 \mathrm{a}$ \\
\hline \multicolumn{4}{|l|}{ February } \\
\hline$T t$ & $4.30 \mathrm{~b}$ & $125 a$ & $0.037 \mathrm{~b}$ \\
\hline$T t P$ & $7.65 \mathrm{a}$ & $125 a$ & $0.062 \mathrm{a}$ \\
\hline LI & $6.12 \mathrm{a}$ & $115 a$ & $0.055 \mathrm{a}$ \\
\hline
\end{tabular}

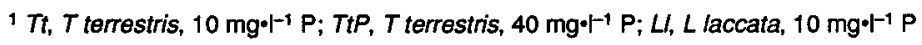

those in $T t$ both in November and in February. A was higher in TtP than in $L /$ in November but not in February. In November, TtP was characterized by $g$ values significantly higher than those in the other treatments, while in February there was no significant difference for this parameter.

Water-use efficiency in $T t P$ and $L /$ was significantly higher than that in $T t$ in both experiments. There was no significant differences between $T t P$ and $L I$. For a given treatment, the WUE values were identical for the two experiments.

Figure 1 gives an insight into the WUE regulation at the individual level prior to transplanting. The regression lines were forced through the origin so that their slopes (water-use efficiency) could be compared. In November as well as in February, the invididual variability of the plots relative to treatments $T t P$ and $L I$ was ordered along the same linear relationship expressing proportionality between $A$ and $g$ and thus constancy of WUE both for the individual plants and the two dates. In con- trast, treatment $T t$ did not exhibit such a control of WUE at the individual level since no significant $(P<0.05)$ correlation between $A$ and $g$ was observed for this treatment. Moreover, the plots of the latter treatment occupied a lower position in the $(A, g)$ graphs, thus indicating lower WUE.

Transplanting resulted in a marked decrease of $A$ between day 0 and day 4 in all treatments and for the 2 measurement periods (fig 2). In February, the decrease of $A$ continued until $18 \mathrm{~d}$ after transplanting for treatment $L$, while a slight recovery of $A$ was observed from d 4 in treatments $T t$ and $T t P$. Such a recovery was not apparent in November, when the decrease in $A$ was more pronounced in the TtP seedlings than it was in the $L /$ seedlings, since the $A$ values of these treatments were significantly different at day 0 , but were not different 18 d after transplanting (fig 2). In February, a very different pattern was observed with the decrease of $A$ being the most pronounced in $\mathrm{Ll}$. 


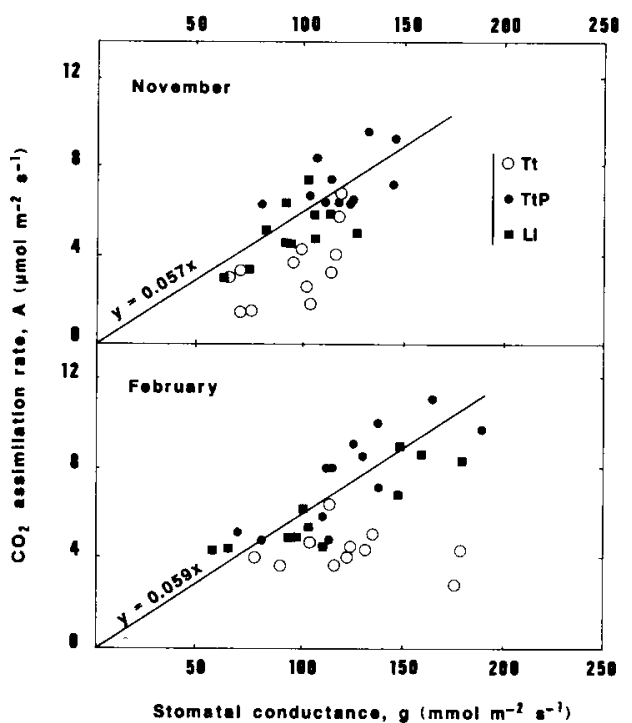

Fig 1. Carbon dioxide assimilation rate $(A)$ of Douglas-fir seedlings inoculated with different ectomycorrhizal fungi in relation to stomatal conductance $(g)$. Regression lines were forced through the origin and refer to the pooled individual plots of treatments TtP and LI. Measurements were made just before transplanting (day

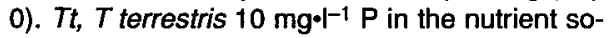
lution; TtP, $T$ terrestris, $40 \mathrm{mg}^{\circ} \mathrm{I}^{-1} \mathrm{P} ; L I, L$ laccata, $10 \mathrm{mg}^{-1} \mathrm{P}$.

Transplanting also affected $g$ (fig 3 ) in a manner approximately identical with the effects on $A$. However, the decrease of $g$ was less pronounced than that of $A$, particulariy during the first $4 \mathrm{~d}$ after transplanting. In February, the recovery of $g$ in treatments $T t P$ and $T t$ took place only from $d$ 11 , and a recovery of $g$ was also observed in treatment $L$.

In figure 4 the gas exchange data of figures 2 and 3 are presented in $A$ vs $C_{i}$ graphs. For both measurement periods and in all treatments the decline of $A$ in response to transplanting was accompanied by increasing $C_{i}$, and was primarily due to

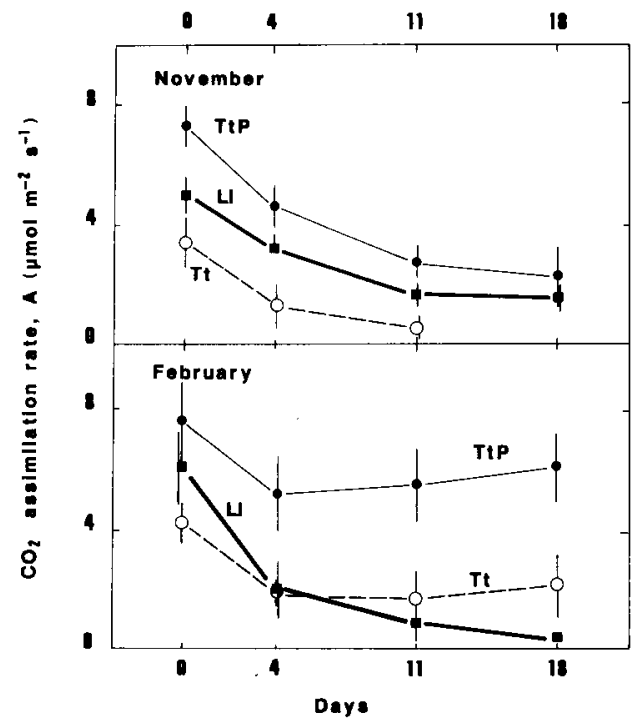

Fig 2. Time-course of $\mathrm{CO}_{2}$ assimilation rate (A) after transplanting in Douglas-fir seedlings inoculated with different ectomycorrhizal fungi. Transplanting was carried out on day 0 , after gas exchange measurements. Vertical bars denote confidence intervals of the mean values $(P$ $<0.05), n=11$ or 12 . $T t, T$ terrestris, $10 \mathrm{mg} \cdot 1-1$ $P$ in the nutrient solution; TtP, $T$ terrestris, 40 $\mathrm{mg} \cdot \mathrm{I}^{-1} \mathrm{P} ; \mathrm{Ll}, \mathrm{L}$ laccata, $10 \mathrm{mg} \cdot \mathrm{I}^{-1} \mathrm{P}$.

alterations in the photosynthetic demand for $\mathrm{CO}_{2}$ while the supply function (related to stomatal conductance) was affected only to a minor extent.

\section{Root and mycorrhizal regeneration}

Root (fig 5) and mycorrhizal (fig 6) regeneration of the transplanted seedlings occurred from $\mathrm{d} 11$ after transplanting in November, and from d 4 in February. Root regeneration was the highest in treatment $T$ T $P$ for both periods and was markedly lower in the other treatments (fig 5). The 


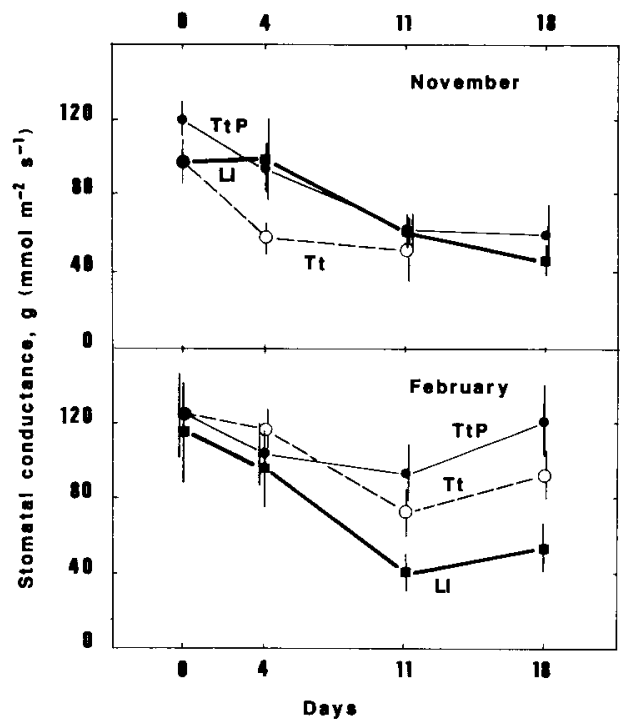

Fig 3. Time-course of stomatal conductance (g) after transplanting in Douglas-fir seedlings inoculated with different ectomyccorhizal fungi. Transplanting was carried out on day 0 , after gas exchange measurements. Vertical bars denote confidence intervals of the mean values ( $P$ $<0.05), n=11$ or 12 . Tt, $\mathrm{T}$ terrestris, $10 \mathrm{mg}^{\cdot 1-1}$ $P$ in the nutrient solution; TtP, $T$ terrestris, 40 $\mathrm{mg} \cdot \mathrm{I}^{-1} \mathrm{P} ; \mathrm{Ll}$, L laccata, $10 \mathrm{mg}^{\mathrm{I}^{-1}} \mathrm{P}$.

seedlings of treatment TtP also had the highest mycorrhizal regeneration in February (fig 6), but not in November. Mycorrhizal regeneration in the $L /$ treatment was identical to that in TtP and superior to that in $T t$ in November, but was noticeably lower than that in the other treatments in February.

\section{Water and nutrient status}

No significant alteration in $\psi_{w p}$ was observed after transplanting in any of the treatments and all treatments had similar $\psi_{w p}$ values ranging from -0.8 to $-0.6 \mathrm{MPa}$ (data not shown).

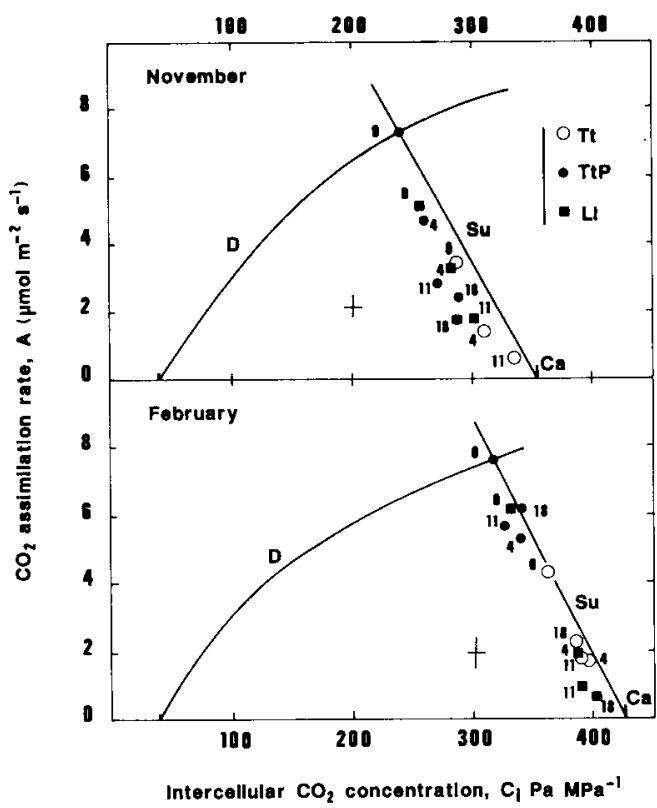

Fig 4. Carbon dioxide assimilation rate (A) against intercellular $\mathrm{CO}_{2}$ concentration (Ci) in transplanted Doulas-fir seedlings from day 0 (before transplanting) to day 18 after transplanting. Numbers in the figure are days after transplanting. The photosynthetic $\mathrm{CO}_{2}$ demand (D) and supply (Su) functions have been shown only at day $\mathrm{O}$ and for treatment $T t P$. Ca, ambient $\mathrm{CO}_{2}$ concentration; November, $\mathrm{Ca}=350$

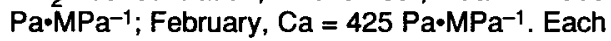
point is a mean value of 11 or 12 replicates. Bars denote mean confidence intervals for $A$ and $\mathrm{Ci}$. $T \mathrm{t}, \mathrm{T}$ terrestris, $10 \mathrm{mg} \cdot \mathrm{I}^{-1} \mathrm{P}$ in the nutrient solution; $T t P, T$ terrestris, $40 \mathrm{mg}^{-1} \mathrm{P} ; \mathrm{LI}$, $L$ laccata, $10 \mathrm{mg}^{-1}{ }^{-1} \mathrm{P}$.

Before transplanting, needle $P$ concentration was significantly higher in the $T t P$ seedlings than in the other treatments (fig 7). Treatments $T t$ and $L /$ had identical needle $r$ concentrations in November, while in February the needle $P$ concentration was slightly but significantly higher in $L /$ than in $T$ t. In February, transplanting significantly 


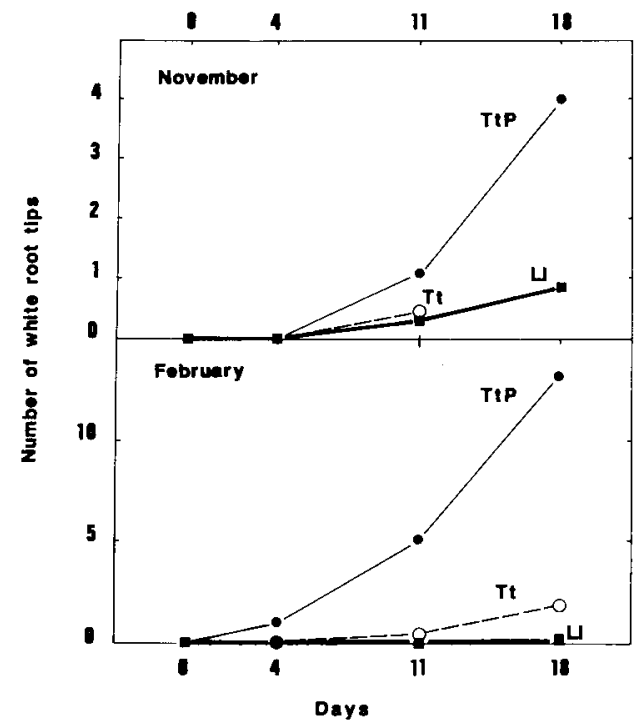

Fig 5. Time-course of root regeneration after transplanting in Douglas-fir seedlings inoculated with different ectomycorrhizal fungi. Transplanting was carried out on day 0 . Tt, $T$ terrestris, $10 \mathrm{mg}^{-1} \mathrm{P}$ in the nutrient solution; TtP, $T$ terrestris, $40 \mathrm{mg} \cdot \mathrm{I}^{-1} \mathrm{P} ; \mathrm{LI}, \mathrm{L}$ laccata, $10 \mathrm{mg} \cdot \mathrm{I}^{-1} \mathrm{P}$. Data are mean values of 12 replicates.

reduced the needle $P$ content in $T t P$, while this concentration remained unchanged in the other treatments.

Needle $\mathrm{N}$ concentration in the $L /$ treatment was significantly lower than those of treatments $T t$ and $T t P$ in November and lower than in TtP in February (fig 8). The seedlings of treatment $T t$ had higher $N$ concentrations in February (fig 8). The seedlings of treatment $T t$ had higher $\mathrm{N}$ concentrations in February than in November, while no seasonal changes occurred in the other treatments. Transplanting had no significant effect on needle $\mathrm{N}$ concentration in any of the treatments.

Gas exchange parameters of the individual plants were examined with respect to their needle nutrient status. There was

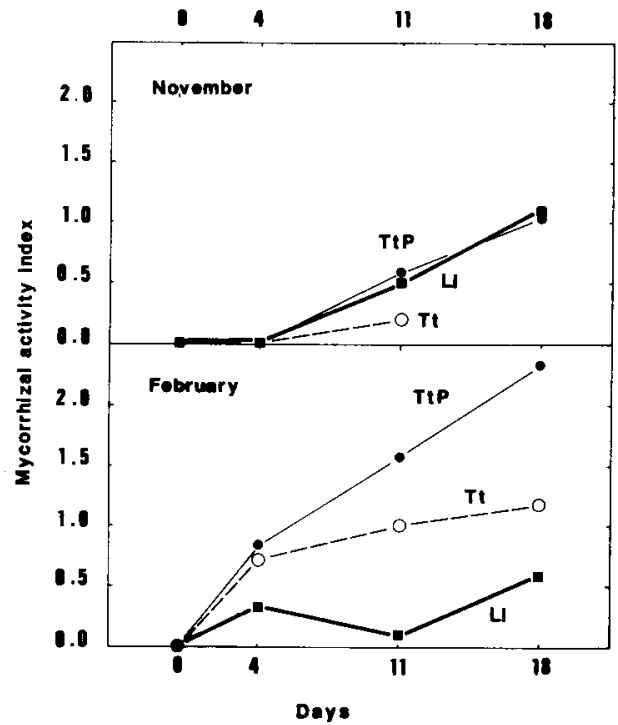

Fig 6. Time-course of mycorrhizal regeneration after transplanting in Douglas-fir seedlings inoculated with different ectomycorrhizal fungi. Transplanting was carried out on day $0 . T t, T$ terrestris, $10 \mathrm{mg}^{-1} \mathrm{P}$ in the nutrient solution; $T t P, T$ terrestris, $40 \mathrm{mg}^{-1} \mathrm{P}^{-1} L$, L laccata, 10 $\mathrm{mg} \cdot \mathrm{I}^{-1} \mathrm{P}$. Data are mean values of 12 replicates.

no relationship between these parameters and the needle $\mathrm{N}$ concentrations. There was a significant correlation between $\boldsymbol{A}$ and needle $P$ concentration only in treatment $T t$ (fig 9a), in the other treatments $A$ was not related to $P$. Stomatal conductance was significantly correlated with $P$ via a parabolic function (fig 9b), with the minimum of $g$ occurring at about 2000 $\mu \mathrm{g} \cdot \mathrm{g}^{-1} P$ in the needles. The clearest picture of limiting effect due to $P$ was observed relative to the WUE data shown in figure 9c: there was a close linear relationship between WUE in treatment $T t$, while the plots relative to treatments $L I$ and $T t P$ occupied the non-limiting $P$ region ( $P$ concentration superior to $700 \mu \mathrm{g}^{\circ} \mathrm{g}^{-1}$ ) of the general relationship. 


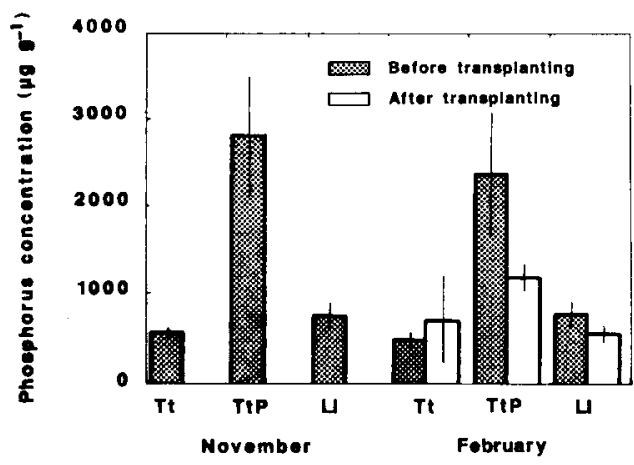

Fig 7. Needle phosphorus concentrations in the different treatments before (November and $\mathrm{Fe}$ bruary) and 18 days after (February only) transplanting. $T t, T$ terrestris, $10 \mathrm{mg}^{\circ-1} \mathrm{P}$ in the nutrient solution; TtP, $T$ terrestris, $40 \mathrm{mg}^{\circ} \mathrm{l}^{-1} \mathrm{P} ; \mathrm{LI}$, $L$ laccata, $10 \mathrm{mg}^{\circ} \mathrm{l}^{-1} \mathrm{P}$. Vertical bars denote confidence intervals of the mean values $(P<$ $0.05), n=8$ to 12 .

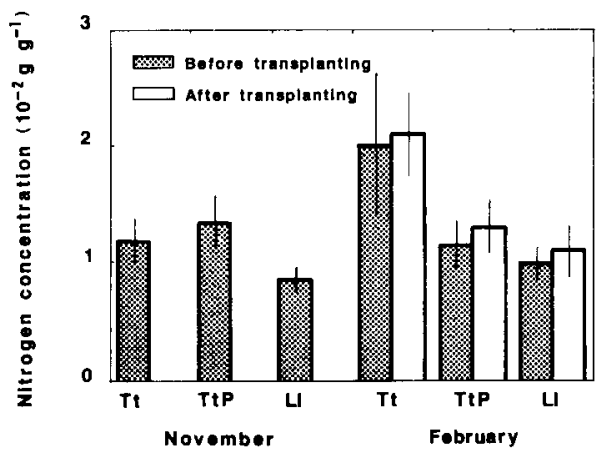

Fig 8. Needle nitrogen concentrations in the different treatments before (November and $\mathrm{Fe}$ bruary) and 18 days after (February only) transplanting. $T t, T$ terrestris, $10 \mathrm{mg}^{\circ-1} \mathrm{P}$ in the nutrient solution; $T t P, T$ terrestris, $40 \mathrm{mg}^{-1} \mathrm{P}$; $L I, L$ laccata, $10 \mathrm{mg}^{-1} \mathrm{P}$. Vertical bars denote confidence intervals of the mean values $(P<$ $0.05), n=8$ to 12 .

\section{DISCUSSION}

The seedlings associated with $T$ terrestris and supplied with a non-limiting (40
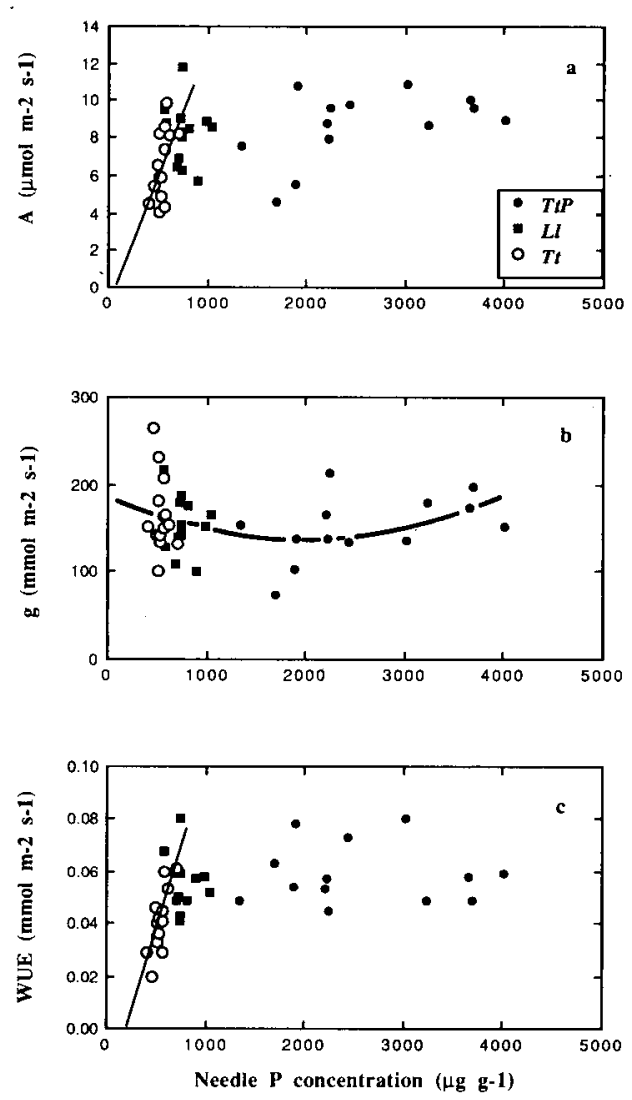

Fig 9. (a) Carbon dioxide assimilation rate $(A)$, (b) Stomatal conductance (g) and (c) Water-use efficiency (WUE) against needle $P$ concentration in the individual plants of the different treatments. Data from November and February were pooled. Regression lines in figure $9 \mathrm{a}$ and $9 \mathrm{c}$ refer to treatment Tt only $(A=0.014 \mathrm{P}-1.00, R=$ $0.56 ;$ WUE $=0.00012 \mathrm{P}-0.25, \mathrm{R}=0.77 ; n=13$ ). Figure 9b, $g=185-4.71 \times 10^{-2} \mathrm{P}+1.19 \times 10^{-5}$ $P^{2}$ (pooled data), $\left.r=0.30, n=40\right) T t, T$ terrestris, $10 \mathrm{mg}^{\circ} \mathrm{l}^{-1} \mathrm{P}$ in the nutrient solution; TtP, $T$ terrestris, $40 \mathrm{mg}^{-1} \mathrm{P} ; \mathrm{Ll}$, L laccata, $10 \mathrm{mg}^{-1} \mathrm{P}$. Vertical bars denote confidence intervals of the mean values $(\mathrm{P}<0.05), \mathrm{n}=8$ to 12 .

$\mathrm{mg} \cdot \mathrm{I}^{-1}(P)$ nutrient solution were taller and had a higher biomass that the seedlings associated with $T$ terrestris but supplied with a $10 \mathrm{mg}^{-1}$ (P) solution. Seedlings mycorrhizal with $L$ laccata and grown un- 
der limiting $P$ conditions $\left(10 \mathrm{mg}^{-1} \quad P\right.$ ) were taller than the seedlings infected with $T$ terrestris and supplied with the same soIution (table I). However, both root collar diameter and total plant biomass were not significantly different between the two latter treatments. Harley and Smith (1983) and Guehl et al (1990) have reported similar results indicating $\mathrm{i}$ ), that the extent to which growth was affected by ectomycorrhizal infection will depend on the fungal species and strain used as mycobiont and ii), that there may be a discrepancy between effects of mycorrhizae on stem elongation on the one hand and on diameter and weight growth on the other. Tyminska et al (1986) observed higher biomass growth in Pinus silvestris seedlings infected with $L$ laccata than in seedlings infected with $T$ terrestris over a wide range of $P$ concentrations in nutrient solution (0.1-31 $\left.\mathrm{mg} \mathrm{I}^{-1}\right)$. These authors also observed that the difference in biomass between the two treatments was not accompanied by a significant difference in needle $P$ concentration, and suggested the stimulating effect of Laccaria laccata - even observed in seedlings with a low percentage of mycorrhizal roots - to be related to the capacity of this fungus to produce growth regulators such as indole acetic acid (IAA). They supported this assumption by the work of Ek et al (1983) who found that the same strain of $L$ laccata produced large quantities of IAA. In the present study with Pseudotsuga menziesii as the host plant, significant differences in needle $P$ concentrations were found between $T t$ and $L I$ (figs 7 and 9). Furthermore, needle $P$ concentration in $L /$ was intermediate between those in $T t$ and $T t P$. That the growth stimulating effect of Laccaria laccata is mediated, at least partially, by a $P$ nutritional effect cannot be precluded here.

In the present study, the superiority of $L$ laccata as compared to $T$ terrestris was also observed relative to the $\mathrm{CO}_{2}$ assimilation characteristics of the seedlings at the end of the first growing season. As compared with the $T t$ seedlings, needle surface area (table I) and $\mathrm{CO}_{2}$ assimilation rates (table II) of the $L /$ seedlings were about 42 and $48 \%$ higher, respectively, thus conferring to the $\mathrm{L}$ seedlings a whole plant $\mathrm{CO}_{2}$ assimulation capacity about 2.1 times that in the $T t$ seedlings and approximately equivalent to that in the TtP seedlings. Several authors (Jones and Hutchinson, 1988; Guehl et al, 1990) have reported similar modulations of host plant $\mathrm{CO}_{2}$ assimilation capacity due to the nature of the mycobiont. $\mathrm{CO}_{2}$ assimilation rate was clearly $P$ limited in treatment $T t$ (fig 9a). Using $31 P$ nuclear magnetic resonance, Foyer and Spencer (1986) studied the effects of reduced phosphate supply on intracellular orthophosphate (Pi) distribution and photosynthesis in Hordeum vulgare leaves. They observed that i), over a wide range of leaf $\mathrm{Pi}$, the cytoplasmic $\mathrm{Pi}$ level is maintained constant, while the vacuolar $\mathrm{Pi}$ is allowed to fluctuate in order to buffer the $\mathrm{Pi}$ in the cytoplasm and ii), that an overall minimum cytoplasmic $\mathrm{Pi}$ concentration of between $5-10$ mmol-1-1 is required to sustain optimal rates of photosynthesis in the light. Despite the relatively high $P$ concentrations found in our study in all the $L /$ and $T t P$ seedlings, some seedlings of these treatments exhibited very low $A$ values (fig $9 a)$. Thus, other limiting factors are likely to be involved.

Water-use efficiency was higher and less variable in $L /$ than in $T t$ (table II, fig 1 ). Guehl et al (1990) observed that Pinus pinea seedlings associated with different ectomycorrhizal fungi were characterized by higher and less variable WUE values than non-mycorrhizal plants. This result is of great importance, since it indicates that ectomycorrhizal infection may confer enhanced drought adaptation to the host 
plant, not only by improving water uptake (Druddridge et al, 1980) and plant water relations (Boyd et al, 1985), but also through higher WUE. In the present study, the data of figure $9 \mathrm{c}$ suggest that the improvement of WUE in the $L$ laccaria infected seedlings as compared to the $T$ terrestris seedlings is mediated by a nutritional $P$ effect involving both effects on $A$ (fig 9a) and $g$ (fig 9b). It is worth noting that there was a clear tendancy for $g$ to be increased when total leaf $P$ was lower than 2000 $\mu \mathrm{g} \cdot \mathrm{g}^{-1}$. In Zea mays, Wong et al (1985) observed a dramatic decrease in $A$ without any effect on WUE ( $A / g$ ratio) when $P$ in the nutrient solution was decreased from 41 to $1.2 \mathrm{mg}^{-1}-1$. However, in Pinus radiata, Conroy et al (1988) found lower WUE in $P$ deficient plants (needle $P$ concentration $700-800 \mu \mathrm{g}^{\circ} \mathrm{g}^{-1}$ ) than in non deficient plants (needle $P$ between 1000 and 1500 $\left.\mu g \cdot g^{-1}\right)$. Thus, their critical value (800 $\mu \mathrm{g} \cdot \mathrm{g}^{-1}$ ) was the same as in our experiments. Harris et al (1983) found that in leaf discs of Spinacia oleracea, low $P_{i}$ led to a loss of stomatal control and wide stomatal apertures, while high $\mathrm{Pi}$ induced stomatal closure. In the same species, Herold (1978) observed that mannose and deoxyglucose induced wilting by metabolically sequestering $\mathrm{Pi}$. Feeding $\mathrm{Pi}$ deficient Hordeum vulgare and Spinacia oleracea cut leaves with $\mathrm{Pi}$ through the xylem transpiration flow, Dietz and Foyer (1986) observed a short-term (5 min) increase in $\mathrm{CO}_{2}$ assimilation and a concurrent decrease in transpiration, resulting in a marked increase of WUE.

Transplanting markedly reduced $A$ in all treatments in both experimental periods (fig 2). Analysing gas exchange data in $A$ vs $C_{i}$ graphs (fig 4) clearly established that this decline of $A$ occurred while the diffusional $\mathrm{CO}_{2}$ supply to the chloroplasts was enhanced $\left(C_{i}\right.$ increased), thus indicating that the changes in $A$ were primarily due to alterations of the mesophyll photosynthetic capacity. Guehl et al (1989) reached the same conclusions with transplanted $\mathrm{Ce}$ drus atlantica seedlings. Our results also indicate that the decline in $A$ cannot be accounted for by alterations in plant water status and in needle nutrient status ( $\mathrm{N}$ and P). The only significant effect of transplanting on needle nutrient status was the decrease found for $P$ in the $T t P$ seedlings in February, in which the recovery of $A$ after transplanting was most marked. The nature of the factor triggering the decline of $A$ remains unknown. In a previous study (Guehl et al, 1989) it has been established for transplanted Cedrus atlantica seedlings that the recovery of $A$, following the initial phase of decline, was concomitant with root regeneration. The results obtained here (figs $2,5,6$ ) suggest that the recovery of $A$ was related to the recovery of mycorrhizal activity rather than regeneration of elongating non-mycorrhizal white root tips. Two mechanisms could be involved: production of growth regulators by the growing fungus, and/or improvement of water and mineral uptake through the reestablishment of mycelial connections between the root and the soil. Our results also show that the ability of the plants to regenerate mycorrhizae after transplanting is affected by seasonal parameters as well as their ability to regenerate roots (Ritchie and Dunlap, 1982).

\section{ACKNOWLEDGMENTS}

This work was supported by a grant from the Office National des Forêts. The authors are grateful to R Zimmermann from the University of Bayreuth (FRG) for mineral analyses. They wish to thank $\mathrm{JL}$ Churin, B Clerc, JM Desjeunes, P Gross and F Willm, INRA Nancy, for their technical assistance and JL Muller for drawing the figures. They are grateful to Pr B Dell (Murdoch university, Perth, Australia) for reviewing the manuscript. 


\section{REFERENCES}

Boyd R, Furbank RT, Read DJ (1986) Ectomycorrhiza and the water relations of trees. In: Proc 1st Eur Symp on Mycorrhizae: Physiology and Genetics (Gianinazzi-Pearson Y, Gianninazzi S, eds) 1-5 July 1985, Dijon INRA, Paris, 689-693

Caemmerer S, Farquhar GD (1981) Some relationships between the biochemistry of photosynthesis and the gas exchange of leaves. Planta 153, 376-387

Chalot M, Battut PM, Botton B, Le Tacon F, Garbaye J (1988) Recent advances in physiological and practical aspects of ectomycorrhizal effects on tree development. CEcol Applic 9 (4), 333-351

Conroy JP, Küppers $M$, Küppers B, Virgona J, Barlow EWR (1988). The influence of $\mathrm{CO}_{2}$ enrichment, phosphorus deficiency and water stress on the growth, conductance and water used of Pinus radiata D Don. Plant Cell Environ 11, 91-98

Dietz KJ, Foyer C (1986) The relationship between phosphate status and photosynthesis in leaves. Reversibility of the effects of phosphate deficiency on photosynthesis. Planta 167, 376-381

Druddridge JA, Malibari A, Read DJ (1980) Structure and function of mycorrhizal rhizomorphs with special reference to their role in water transport. Nature (Lond) 287, 834-836

Ek M, Ljungquist PD, Stenström E (1983) Indole-3 acetic acid production by mycorrhizal fungi determined by gas chromatographymass spectrometry. New Phytol 94, 401-407

Foyer C, Spencer C (1986) The relationship between phosphate status and photosynthesis in leaves. Effects on intracellular orthophosphate distribution, photosynthesis and assimilate partitioning. Planta 167, 369-375

Guehl JM, Aussenac G (1987) Photosynthesis decrease and stomatal control of gas exchange in Abies alba Mill in response to vapor pressure difference. Plant Physiol 83, 316-322
Guehl JM, Aussenac G, Kaushal P (1989) The effects of transplanting stress on photosynthesis, stomatal conductance and leaf water potential in Cedrus atlantica: role of root regeneration. In: Forest Tree Physiology (Dreyer $\mathrm{E}$ et al, eds) Ann Sci For $46 \mathrm{~S}, 464$ 468

Guehl JM, Mousain D, Falconnet G, Gruez J (1990) Growth, carbon dioxide assimilation capacity and water-use efficiency of Pinus pinea $L$ seedlings inoculated with different ectomycorrhizal fungi. Ann Sci For 47, 91 100

Harley JL, Smith SE (1983) Growth and carbon metabolism of ectomycorrhizal plants. In: $M y$ corrhizal symbiosis (Harley JL, Smith SE, eds) Academic Press, London 183-200

Harris GC, Cheesbrough JK, Walker DA (1983) Measurement of $\mathrm{CO}_{2}$ and $\mathrm{H}_{2} \mathrm{O}$ vapor exchange in spinach leaf disks. Plant Physiol 71, 102-107

Herold A (1978) Induction of wilting by mannose in spinach beet leaves. New Phytol 81, 299305

Jones HG (1985) Partitioning stomatal and nonstomatal limitations to photosynthesis. Plant Cell Environ 8, 95-104

Jones MD, Hutchinson TC (1988) Nickel toxicity in Mycorrhizal birch seedlings infected with Lactarius rufus or Scleroderma flavidum. I. Effects on growth, photosynthesis, respiration and transpiration. New Phytol 108, 451459

Le Tacon F, Garbaye J, Carr G (1987) The use of mycorrhizas in temperate and tropical forests. Symbiosis 3, 179-206

Marx DH, Bryan WC, Cordell CE (1977) Survival and growth of pine seedlings with Pisolithus ectomycorrhizae after two years in reforestation sites in North Carolina and Florida. For Sci 22, 363-373

Ritchie GA, Dunlap JR (1980) Root growth potential: its development and expression in forest tree seedlings. NZJ For Sci 10 (1), 218248

Schramel P, Wolf A, Klose BJ (1980) Analytical pre-treatment of biological material by wetashing methods. In: Trace Elements Analytical Chemistry in Medicine and Biology (Brat- 
ter P, Schramel P, eds) Walter de Gruyter and Co Berlin

Tyminska A, Le Tacon F, Chadœuf J (1986) Effect of three ectomycorrhizal fungi on growth and phosphorus uptake of . Pinus silvestris seedlings at increasing phosphorus levels. Can J Bot 64 (11), 2753-2757
Wong SC, Cowan IR, Farquhar GD (1985) Leaf conductance in relation to rate of $\mathrm{CO}_{2}$ assimilation. I. Influence of nitrogen nutrition, phosphorus nutrition, photon flux density and ambient partial pressure of $\mathrm{CO}_{2}$ during ontogeny. Plant Physiol 78, 821-825 